The submilted manuscript has been authored by a contractor of the U.S. Government under contract No. W-31-109-ENG-38. under contract No. Worment retains a nonexclusive. royafty-free license to publish or reproduce the published form of this contribution, or allow others to do so, for U.S. Government purposes.

\title{
Laser Beam Welding of Any Metal
}

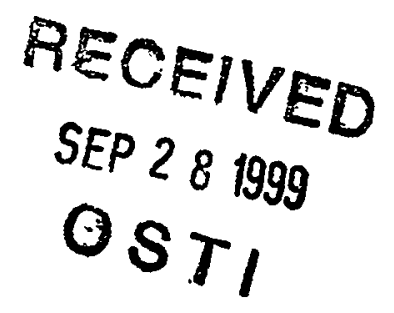

\author{
K.H. Leong and H.K. Geyer \\ Technology Development Division \\ Argonne National Laboratory \\ 9700 S. Cass Avenue, Building 207 \\ Argonne, II 60439
}

\begin{abstract}
The effect of a metal's thermophysical properties on its weldability are examined. The thermal conductivity, melting point, absorptivity and thermal diffusivity of the metal and the laser beam focused diameter and welding speed influence the minimum beam irradiance required for melting and welding. Beam diameter, surface tension and viscosity of the molten metal affect weld pool stability and weld quality. Lower surface tension and viscosity increases weld pool instability. With larger beam diameters causing wider welds, dropout also increases. Effects of focused beam diameter and joint fitup on weldability are also examined. Small beam diameters are sensitive to beam coupling problems in relation to fitup precision in addition to beam alignment to the seam. Welding parameters for mitigating weld pool instability and increasing weld quality are derived from the above considerations. Guidelines are presented for the tailoring of welding parameters to achieve good welds. Weldability problems can also be anticipated from the properties of a metal.
\end{abstract}

\section{INTRODUCTION}

Process development for the laser beam welding of metals has initially tended to be somewhat empirical in nature. This empiricism was perhaps caused by the initial lack of understanding of the process of the interaction of a laser beam with a metallic surface and the proper diagnostic tools. The most common quoted parameters have been the power of the laser beam used and the welding speed $[1,2]$. Adjustment of these two parameters led to optimization of surface weld quality and subsequent characterization of the weld revealed the presence of porosities or cracks and change in microstucture. Tensile or formability tests may also be performed to determine weld strength and suitability for a particular application. Further experimentation led to the determination of helium as the optimal shielding gas with minimum plasma formation and the location of the beam focus below the workpiece surface for maximum weld penetration. Steel has been the primary subject of these early experimentation and weld quality obtained has been excellent for a wide range of process parameters. The laser beam welding of steel is a robust process and has consequently found converts even in the conservative automotive manufacturing area.

Modelling of the welding process has advanced considerably with general understanding of the formation and maintenance of keyhole with results that are in qualitative agreement with experimental observations [e.g., see 3]. However, fundamental understanding is still somewhat lacking. As an example of the state of understanding of the welding process is the welding of aluminum. Some researchers claim that the best welds are obtained by placing the beam focus above the surface while others claim that the focus should be below. Regardless, the concensus is that aluminum is much more difficult to weld than steel. The intent of this paper is to present a 


\section{DISCLAIMER}

This report was prepared as an account of work sponsored by an agency of the United States Government. Neither the United States Government nor any agency thereof, nor any of their employees, make any warranty, express or implied, or assumes any legal liability or responsibility for the accuracy, completeness, or usefulness of any information, apparatus, product, or process disclosed, or represents that its use would not infringe privately owned rights. Reference herein to any specific commercial product, process, or service by trade name, trademark, manufacturer, or otherwise does not necessarily constitute or imply its endorsement, recommendation, or favoring by the United States Government or any agency thereof. The views and opinions of authors expressed herein do not necessarily state or reflect those of the United States Government or any agency thereof. 


\section{DISCLAIMER}

Portions of this document may be illegible in electronic image products. Images are produced from the best available original document. 
logical semi-empirical approach to attain a qualitative understanding of the welding process in regard to the interaction of process parameters and material properties. Consideration of metallurgical properties are also important to obtaining good welds avoiding porosities and cracking but are not considered in this paper.

\section{Keyhole Welding}

Keyhole welding is depicted in Fig. 1. A laser beam that is focused on the metal's surface causes the

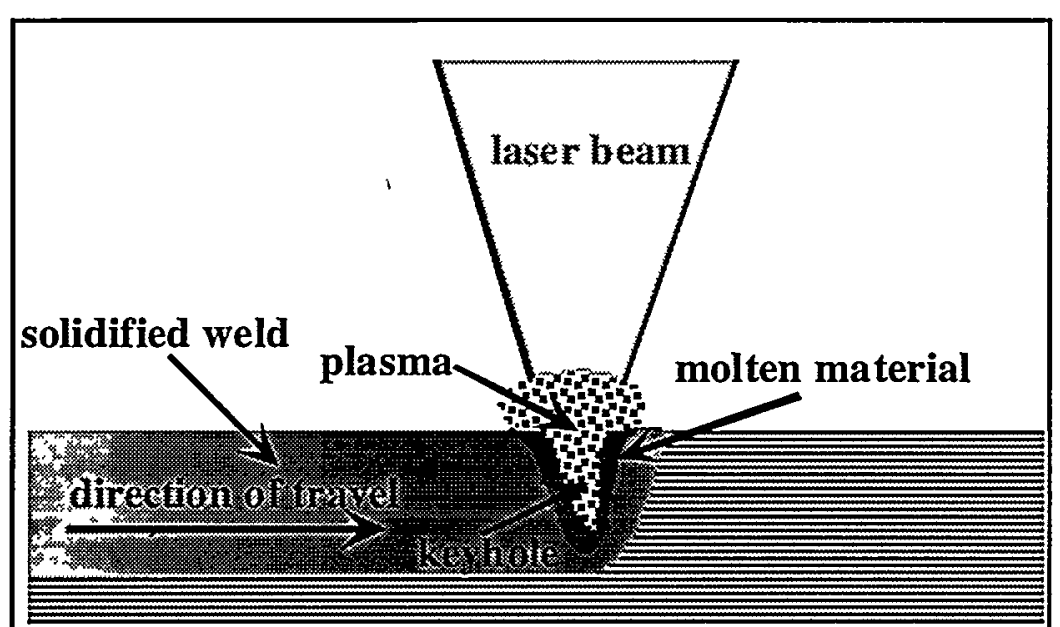

Figure 1. Schematic of keyhole laser beam welding process. formation of a keyhole. For most metals, a beam irradiance of $>0.5 \mathrm{M} \mathrm{W} \mathrm{cm}^{-2}$ is required [6]. An intense plasma is formed inside the keyhole from the the mixture of cover gases and metal vapor. A less intense plasma exists above the keyhole. The keyhole and the surrounding molten metal advances as the beam traverses the metal surface with a solidification front on the trailing side and a melt front on the leading side. Complex circulation patterns of the melt exist inside the keyhole. The use of round beams generally results in the formation of chevron patterns on the weld surface unless unstable weld pools are formed [4]. Weld pool oscillation increases as the welding speed is increased influencing the quality of the resulting weld. For different welding speed and beam power combinations, regimes of weld quality encompassing smooth, ropey, humping, undercut and dropout may result [see 2]. Most of the results that contributed to the understanding of keyhole welding has been obtained on steel, a material that has been proven to be easily weldable. Recent work with different metals has shown that quality welds require a more restrictive range of process parameters. If the effect of the thermophysical properties of metals on the keyhole process are better understood, process parameter development to produce quality welds would be facilitated.

\section{Threshold Irradiance}

The interaction of an intense laser beam with a surface to effect a weld is basically a problem in heat transfer. Consequently, the heat flux effected by the absorption of the laser beam energy and the conduction of heat by the metal are relevant parameters affecting the welding process. The heat flux is dependent on the beam irradiance (not power) and the effective absorptivity for the beam energy. Recently, a simple formulation for the threshold irradiance required for melting a surface was obtained [5]. $\mathrm{I}_{\mathrm{m}}$, the threshold irradiance for melting is given by

$$
I_{m}=\frac{k\left(T_{m e l t}-T_{0}\right)}{A d J_{\max }}
$$

where $\mathrm{k}$ is the thermal conductivity of the metal, $\mathrm{T}_{\text {melt }}$ and $\mathrm{T}_{0}$ are the melting and ambient temperatures, $A$ is the absorptivity of the surface for the laser beam, and $\mathrm{d}$ is the beam diameter at the surface. $\mathrm{J}_{\max }$ has a value of 0.1 for a value of 0.01 of the ratio of the thermal diffusivity to the product of the beam velocity and diameter $(\alpha / \mathrm{vd})$. $\mathrm{J}_{\max }$ increases approximately linearly to 0.51 where it stays approximately constant for $(\alpha / v d)>4$. The irradiance for melting serves as a guide and a lower bound for the irradiance required for welding. It should be noted that a minimum irradiance of $10^{5} \mathrm{Wcm}^{-2}$ is necessary to maintain the keyhole irrespective of $\mathrm{I}_{\mathrm{m}}$ which may have a 
significantly lower value when the absorptivity is high [6]. High beam irradiance is necessary for keyhole welding when absorptivity and beam diameters are small, and thermal conductivity and melting point are high. High irradiance is also necessary for high speed welds particularly when the thermal diffusivity is low. Higher weld penetration and short focal depth of optics used would also increase the irradiance necessary to weld.

Given a metal and its thermophysical properties, Eqn. (1) provides a guide in the choice of the irradiance necessary to form a keyhole. Consequently, the laser beam spot size has to be determined in order to select the appropriate laser beam power. Careful considerations of the process parameters such as weld penetration and speed and optics used will usually give a better approximation for the irradiance. However, the beam irradiance incident on the surface is affected by the presence of the plasma and the weld quality obtained is influenced by the properties of the workpiece.

\section{Shielding Gas and Plasma}

Argon, and helium are the most commonly used inert shielding gas for laser welding to prevent oxidation of the weld metal. Carbon dioxide and nitrogen are not as desirable because dissociation of the molecules may result in reaction with the weld metal. For keyhole laser beam welding, beam irradiances exceed $0.5 \mathrm{MW} \mathrm{cm}-2$ and plasma is formed inside and above the keyhole [see 7]. Helium with an ionization potential of $24.58 \mathrm{eV}$ results in a lower intensity plasma than when $\operatorname{argon}(15.76 \mathrm{eV})$ is used. The effective ionization potential of the shielding gas is lowered by the vaporization of metal atoms from the surface. However, for the same metal vapor fraction helium remains the best shielding gas. The plasma above the keyhole partially absorbs and defocuses the beam, retarding the absorption of beam energy by the keyhole. The plasma in the keyhole is of a higher temperature/intensity and aids in the absorption of the laser beam. The plasma intensity increases as a function of the wavelength of the laser beam used. Lower plasma intensities are obtained with Nd:YAG laser beams compared to $\mathrm{CO}_{2}$ and less costly argon gas is frequently used for Nd:YAG welding without significant loss in weld penetration.

For optimal beam coupling or weld penetration, shielding gas for the top of the weld is delivered via a small nozzle such that the high velocity gas jet retards plasma formation [2]. In practice, the shielding gas can be configured as a cross jet at an angle to the horizontal in a leading or trailing edge configuration along the direction of welding, or transverse to the direction of welding, and as a coaxial flow with the laser beam (see Fig. 2). These different shield gas configurations produce different weld penetrations under the same conditions of beam power and shielding gas flow [8]. In the leading edge configuration (Fig. 2a), the plasma is blown towards the position to be welded in contrast to the trailing edge and transverse configuration where the plasma is blown away. Consequently, the latter two configurations are more effective in preventing plasma formation over the region to be welded and deeper welds are obtained. The weld penetrations obtained for different leading and trailing edge orientations of the cross jet is shown in Fig. 3. The leading edge configuration results in approximately $0.5 \mathrm{~mm}$ lower penetration with no significant change in the weld width. The coaxial shielding gas configuration is also not as effective as the trailing edge or transverse configurations in plasma reduction but tends to produce a better shielding gas configuration. The cross jet configurations tend to entrain some of the ambient air and some oxidation may occur. For some sensitive alloys (e.g., aluminum and vanadium), a shielding shroud has been found to provide improved shielding [9]. Shielding for the bottom of full penetration welds may be required. Similar shielding gas configurations as discussed above may be applied but an effective method is the use of a groove below the joint that is flooded with helium or argon [8]. 


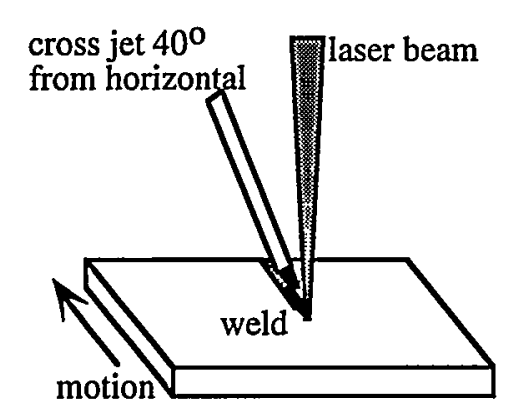

(a) cross jet pointed at leading edge of weld pool

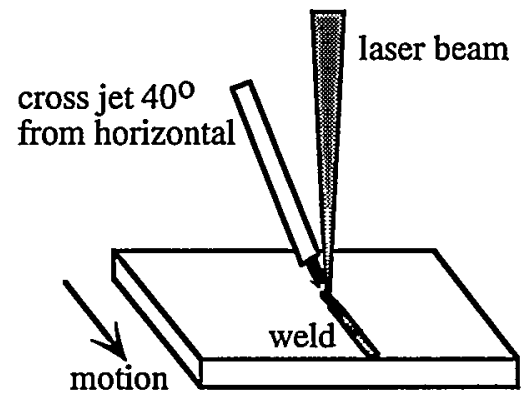

(b) cross jet pointed at trailing edge of weld pool

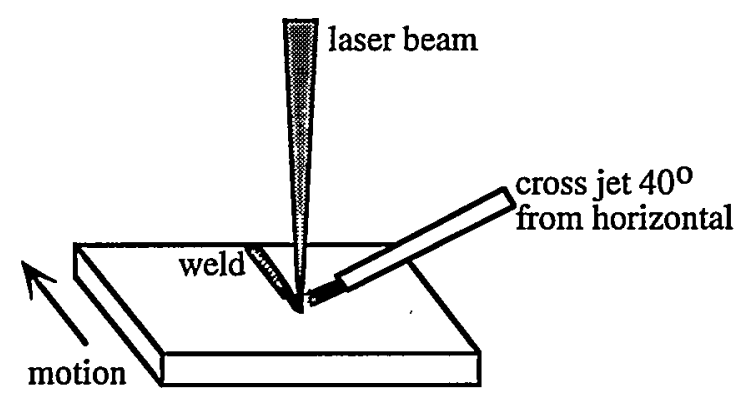

(c) cross jet pointed transverse to welding direction

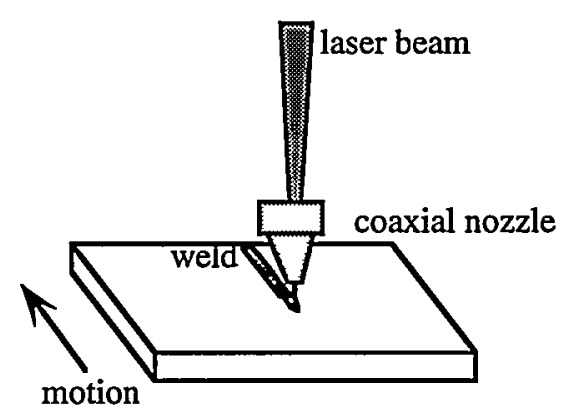

(d) coaxial nozzle

Figure 2. Different top shielding gas configurations for laser beam welding. The angle of $40^{\circ}$ is used as an example.

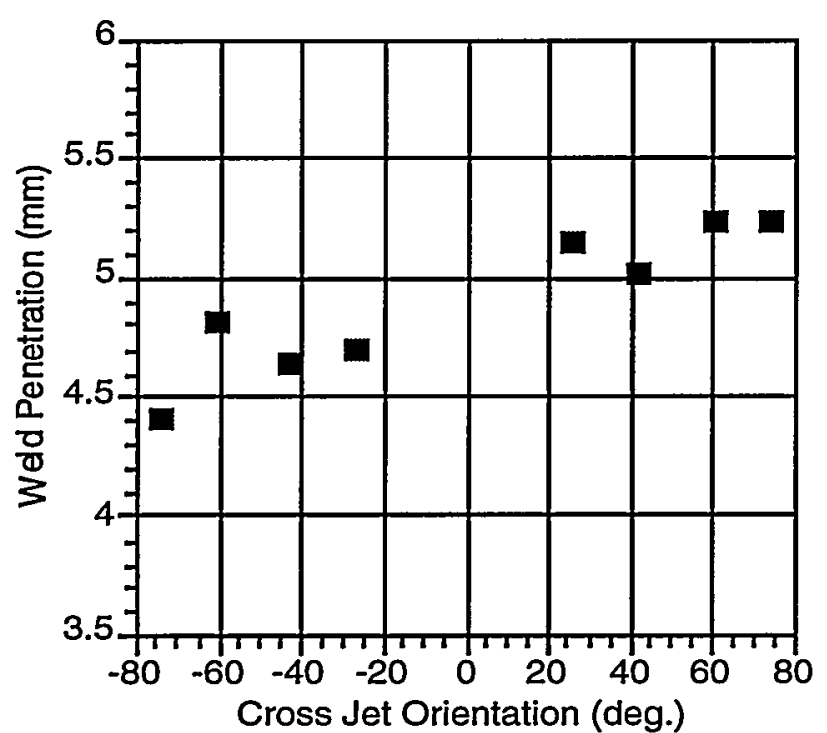

Figure 3a. Weld penetration obtained on steel with a $4 \mathrm{~kW} \mathrm{TEM} \mathrm{TO}_{20} \mathrm{CO}_{2}$ beam and a welding speed of $2.63 \mathrm{~cm} \mathrm{~s}-1.40 \mathrm{cfh}$ of helium was used with the $6.4 \mathrm{~mm}$ diameter cross jet. The negative angles to the horizontal indicate leading edge orientation to the welding direction.

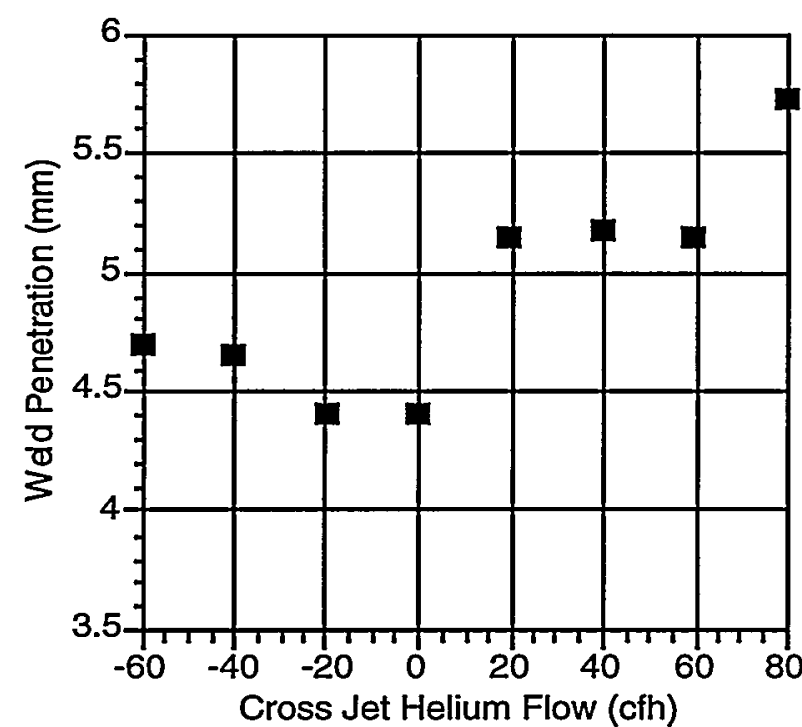

Figure $3 \mathrm{~b}$. Weld penetration obtained for the same process parameters in Fig. 3a. The negative flow values indicate leading edge orientation of the cross jet which was set at $26^{\circ}$ to the horizontal. 
In the welding of alloys, some loss of a more volatile component may occur in the weld. This vaporized component (e.g., magnesium in 5000 series aluminum alloys, zinc in some magnesium alloys) is carried away and cooled by the shielding gas. The magnesium or zinc will condense and deposit downstream of the shielding gas flow. For aluminum or magnesium welds, the trailing edge configuration forms a deposit on the weld surface resulting in a greyish dull surface whereas the transverse configuration results in a dark coating along one side of the weld (see Fig. 4)[8].

\section{Beam Focus Position}

Focused beams have the general characteristic of the smallest size at the focus and a depth of focus that increases with the beam quality and the focal length of the optics used. The focal spot size and depth of focus for circular beams are given by [2]

$$
\begin{aligned}
& \mathrm{d}_{\min }=4 \mathrm{M}^{2} \mathrm{f} \lambda /\left(\pi \mathrm{D}_{1}\right) \\
&=1.27 \mathrm{M}^{2} \mathrm{~F} \lambda \\
& \mathrm{z}_{\mathrm{f}} \sim 1.26\left(\mathrm{M}^{2}\right)^{2} \mathrm{~F}^{2} \lambda
\end{aligned}
$$

where $\mathrm{M}^{2}$ is the conventional beam quality parameter, $\mathrm{f}$ is the focal length, $\lambda$ is the wavelength, $D_{1}$ is the beam diameter at the lens and $F$

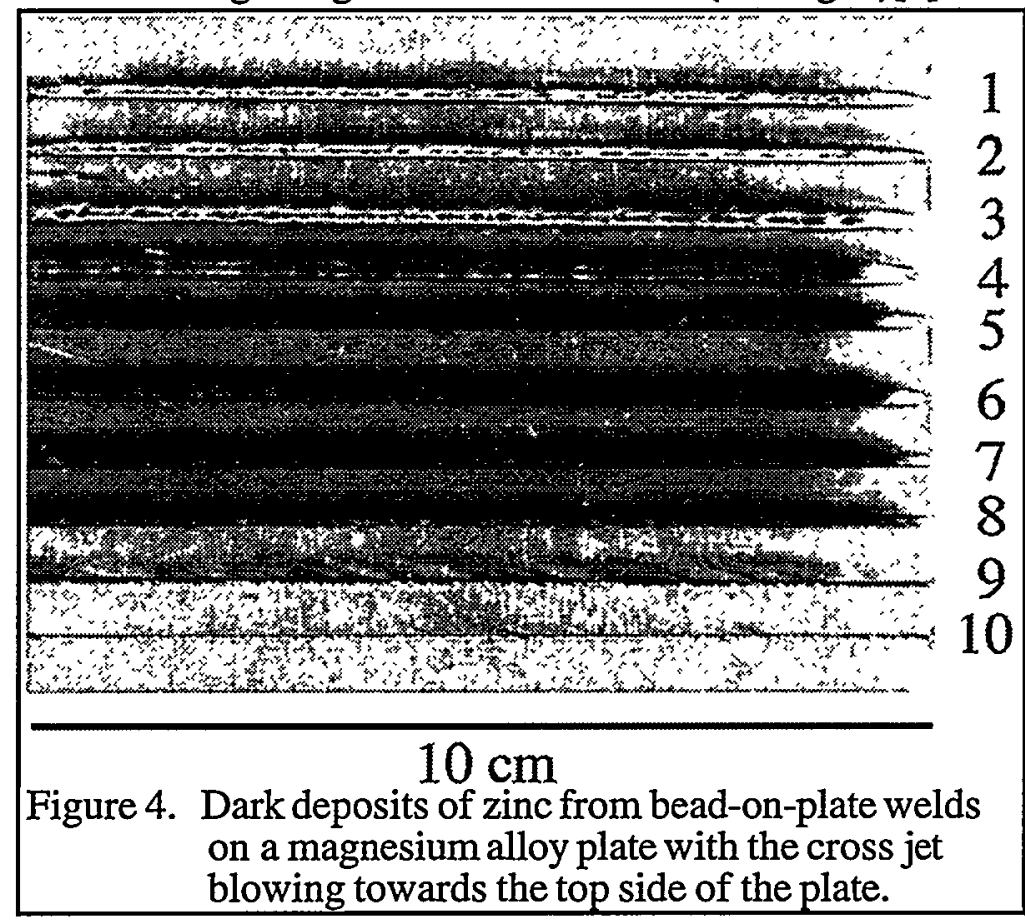
is $f / D_{1}$. Consequently, the optimal location of the beam focus is below the surface at one half the desired weld penetration if the focused beam has an adequate depth of focus.

Recent data on the welding of aluminum has placed the beam focus above the surface [10-12]. A mix of argon and helium was found to result in better welds [12]. Others have found that the conventional method of placing the beam focus below the surface produced more efficient welds with plasma suppression using helium $[9,13]$. Analysis of the different results obtained indicate an interplay of the effects of plasma formation and beam irradiance on weldpool stability given the low viscosity and surface tension of molten aluminum. Having the beam focus above the workpiece surface produces a higher intensity plasma than below the surface. The plasma tends to reduce the beam irradiance to the surface. A blend of argon and helium will produce a higher intensity plasma than pure helium. If the original beam irradiance is high, reduction by the plasma will tend to improve weldpool stability and result in improved welds on aluminum. The authors' assessment is that the best results are obtained using plasma suppression and beam focus below the surface to minimize plasma formation. However, irradiance has to be minimized to improve weldpool stability. This is discussed in more depth in a later section.

\section{Beam Diameter and Part Fitup}

Higher beam irradiance is obtained at smaller focused beam diameters which will result in faster weld speeds at the same weld penetration or deeper penetrations at the same welding speed for a given beam power. In practice, beam spot sizes are specified to allow for part fitup. For steel parts, spot sizes used for the welding of automotive components are often in the range of 0.75 to 1 $\mathrm{mm}$. Consequently, welding efficiency is compromised to meet fitup tolerance. For the case of steel, full penetration high speed laser beam butt welding of thin sheets is a robust process yielding 
high quality welds with minimal undercut and dropout.

Recent experience with aluminum and magnesium alloys indicate a much narrower range of process parameters to produce good welds [see 8-14]. High beam irradiance $\left(>1 \mathrm{MWcm}^{-2}\right)$ is necessary to weld aluminum but dropout and poor surface weld quality tend to result. The tendency to form holes from dropout increases as the material thickness decreases and the beam diameter increases [8]. The above observation is consistent with a molten pool that has low surface tension and viscosity. Dropout is more likely with a lower surface tension liquid whereas weldpool stability decreases with lower viscosity. In the $\mathrm{CO}_{2}$ butt welding of magnesium sheets, incomplete joining of the two interfaces occured frequently [14]. It appeared that, with magnesium having the highest oxidation potential of the metals considered here, the oxide layers prevented fusion of the interfaces. Good welds were obtained but were very sensitive to process parameters. Welding with a pulsed Nd:YAG beam with higher peak irradiances that help break up the oxide layer did not exhibit the same problem. Although magnesium had substantially higher absorptivity for $\mathrm{CO}_{2}$ beams than aluminum, the slightly lower surface tension and viscosity values resulted in narrower process parameter windows for good welds. However, the lower threshold irradiance resulted in improved surface weld quality when good welds are obtained for the case of $\mathrm{CO}_{2}$.

Equation (1) indicates that threshold irradiance can be reduced by increasing the metal's absorptivity using Nd:YAG beams compared to $\mathrm{CO}_{2}$. Martukanitz, et al. have found that good quality welds on aluminum are easier to obtain using $\mathrm{Nd}$ :YAG lasers compared to $\mathrm{CO}_{2}$ [11]. Magnesium is also easier to weld with Nd:YAG beams [14]. Equation (1) also indicates that increasing the beam diameter will also decrease the threshold irradiance [8]. However, the inverse relationship of the threshold irradiance to beam diameter and the constraint in the practical range of beam diameters do not produce as substantial effect as increasing the absorptivity. Consequently, no significant increase in weld quality by increasing spot size has been observed [8].

\section{Welding of Any Metal}

The discussions above have focused on the interaction of process parameters and thermophysical properties of the metal and their effects on weld quality. Analysis of the results of published laser beam welding data indicates that the weldability of a metal and the required process parameters can be predicted. Table 1 lists several metals that cover a broad range in thermophysical properties relevant to the welding process. The properties for the prediction of the threshold irradiance for melting are listed. $J_{\max }$ is determined from the value of $\alpha / \mathrm{vd}$. For a $600 \mu \mathrm{m}$ spot size and welding speed of $8.47 \mathrm{~cm} \mathrm{~s}^{-1}$, the threshold irradiances for melting for the different metals are computed and listed in the bottom of the table. Absorptivities of metals tend to increase with temperature and with the roughness or impurity of the surface[20]. Metals have a higher absorption for shorter wavelength beams and the absorptivities for the Nd:YAG beam are significantly higher than that for $\mathrm{CO}_{2}$. Values of absorptivities at the melting point are not readily available in the literature and comparisons of the values computed in Table 1 are based on the absorptivities listed which are not necessarily at the melting point. These values serve as lower bounds for irradiances necessary to weld [5]. Higher irradiances are necessary for deeper penetration and to overcome the constraints of optics with short depth of focus. In addition, an irradiance of $>0.5 \mathrm{MW} \mathrm{cm}-2$ is necessary to maintain a keyhole [6].

Equation (1) for the threshold irradiance shows that high irradiances $(>1 \mathrm{MW} \mathrm{cm}-2)$ are required for a metal with high values of the thermal conductivity and melting point, high welding speed and small spot sizes, and low values of the absorptivity. Consequently, irradiances over $1 \mathrm{MW} \mathrm{cm}-2$ are necessary to weld aluminum and copper with the $\mathrm{CO}_{2}$ laser and lower irradiances are required when the Nd:YAG laser is used. Zinc, on the other hand is a low melting point metal and requires an irradiance $\ll 1 \mathrm{MW} \mathrm{cm}-2$ to melt. Keyhole welding (irradiances $>0.5 \mathrm{MW} \mathrm{cm}-2$ ) would be 
difficult as rapid vaporization and spatter would occur. Vanadium has the highest melting point of the metals listed but the irradiance is aided by the low thermal conductivity and higher absorptivity compared to aluminum.

Table 1. Thermophysical Properties of Different Metals [6, 7, 15-22]

\begin{tabular}{|c|c|c|c|c|c|c|c|}
\hline $\begin{array}{l}\text { Thermophysical } \\
\text { Parameter }\end{array}$ & $\mathrm{Al}$ & $\mathrm{Cu}$ & $\mathrm{Fe}$ & $\mathrm{Mg}$ & $\mathrm{Ti}$ & V & $\mathrm{Zn}$ \\
\hline Melting point $T_{m}(K)$ & 933 & 1357 & 1808 & 923 & 1938 & 2170 & 693 \\
\hline Boiling point $T_{b}(K)$ & 2333 & 2840 & 3003 & 1380 & 3560 & 3653 & 1203 \\
\hline $\begin{array}{l}\text { Density }\left(10^{3} \mathrm{~kg} \mathrm{~m}^{-3}\right) \\
\text { solid at } 293 \mathrm{~K} \\
\text { liquid at } T_{\mathrm{m}}\end{array}$ & $\begin{array}{l}2.70 \\
2.38\end{array}$ & $\begin{array}{l}8.92 \\
8.00\end{array}$ & $\begin{array}{l}7.86 \\
7.03\end{array}$ & $\begin{array}{l}1.74 \\
1.59\end{array}$ & $\begin{array}{l}4.5 \\
4.13\end{array}$ & $\begin{array}{l}5.96 \\
5.36\end{array}$ & $\begin{array}{l}7.14 \\
6.58\end{array}$ \\
\hline $\begin{array}{l}\text { Vapor pressure }(\mathrm{Pa}) @ \\
\mathrm{~T}_{\mathrm{m}} \\
1000 \mathrm{~K} \\
2000 \mathrm{~K} \\
3000 \mathrm{~K}\end{array}$ & $\begin{array}{c}10^{-6} \\
12 \times 10^{-6} \\
900\end{array}$ & $\begin{array}{c}4.3 \times 10^{-2} \\
1.5 \times 10^{-6} \\
380\end{array}$ & $\begin{array}{c}2.3 \\
0 \\
22\end{array}$ & $\begin{array}{r}360 \\
1360\end{array}$ & $\begin{array}{l}0.53 \\
0 \\
1.2 \\
6918\end{array}$ & $\begin{array}{c}3.3 \times 10^{-3} \\
0 \\
3.1 \times 10^{-4} \\
6.5\end{array}$ & $\begin{array}{r}23 \\
12000\end{array}$ \\
\hline Viscosity@ $\mathrm{T}_{\mathrm{m}}$ (mPa s) & 2 & 4.34 & 6.9 & 1.25 & 5.2 & unavailable & 3.5 \\
\hline $\begin{array}{l}\text { Surface tension @ } T_{m} \\
(\mathrm{~N} / \mathrm{m})\end{array}$ & 0.91 & 1.30 & 1.87 & 0.56 & 1.65 & 1.95 & 0.78 \\
\hline $\begin{array}{l}\text { Thermal conductivity of } \\
\text { solid @ } T_{m} \\
\left(W^{-1} \mathrm{~K}^{-1}\right)\end{array}$ & 210 & 330 & 30 & 130 & 28 & 50 & 9 \\
\hline $\begin{array}{l}\text { Thermal diffusivity of } \\
\text { solid @ } T_{m} \\
\left(\mathrm{~cm}^{2} \mathrm{~s}^{-1}\right)\end{array}$ & 0.68 & 0.79 & 0.063 & 0.65 & 0.082 & 0.11 & 0.32 \\
\hline $\begin{array}{l}\text { Absorptivity } @ \mathrm{~T}_{\mathrm{m}}(\%) \\
1.06 \mu \mathrm{m} \\
10.6 \mu \mathrm{m}\end{array}$ & $\begin{array}{l}11 \\
3\end{array}$ & $\begin{array}{c}1.3 @ 300 \mathrm{~K} \\
5\end{array}$ & $\begin{array}{c}36 @ 300 \mathrm{~K} \\
5 @ 300 \mathrm{~K}\end{array}$ & $3 @ 300 \mathrm{~K}$ & $\begin{array}{l}37 @ 300 \mathrm{~K} \\
9.4 @ 300 \mathrm{~K}\end{array}$ & $\begin{array}{r}\sim 45 \\
5\end{array}$ & $\begin{array}{c}42 @ 300 \mathrm{~K} \\
10\end{array}$ \\
\hline $\begin{array}{l}\text { Threshold irradiance for } \\
\text { melting for a spot size } \\
\text { of } 600 \mu \mathrm{m} \text { and a weld } \\
\text { speed of } 8.47 \mathrm{~cm} \mathrm{~s}^{-1} \\
(\mathrm{MW} \mathrm{cm}-2) \\
\text { Nd:YAG and } \mathrm{CO}_{2}\end{array}$ & $\begin{array}{c}0.42 \\
1.5\end{array}$ & 2.4 & $\begin{array}{l}0.068 \\
0.49\end{array}$ & 0.95 & $\begin{array}{l}0.043 \\
0.17\end{array}$ & $\begin{array}{l}0.099 \\
0.89\end{array}$ & $\begin{array}{c}0.0032 \\
0.016\end{array}$ \\
\hline
\end{tabular}

Keyhole or weldpool stability is important for the formation of high quality weld surfaces that have minimal humping or undercut. From the point of instability phenomenon, a more intense driving force coupled with a lower viscosity or surface tension liquid will tend to produce higher instability. Weldpool instability is driven by the beam irradiance. When high irradiance is applied to molten metals with low viscosity and surface tension, weldpool instability will tend to increase. Consequently, using $\mathrm{CO}_{2}$ beams to weld aluminum and magnesium is problematic whereas the Nd:YAG beam with lower required irradiance can produce higher quality welds $[11,14]$. With low viscosity and surface tension alloys, high irradiance tends to produce spatter, undercut, porosity and dropout. However, a narrow range of irradiance and process parameter values may 
produce reasonable welds $[8,9,14]$. Iron and steel alloys can be laser beam welded over a wide range of beam parameters. Copper and titanium with similar viscosity and surface tension values are also readily weldable [see 1]. Although the viscosity of vanadium is not available, the value of the surface tension and the good weldability would indicate that the value is similar to that of iron.

Alloys consist of the base metal with other metals added to improve material strength or weldability. In the welding process, the weld metal is subjected to high temperature and some alloy constituents with high vapor pressure may be depleted. For example, the high vapor pressure of magnesium at the melting point of aluminum would indicate significant losses evident in the black deposits downstream of the cross jet. The zinc in magnesium alloys would also behave similarly. Lower beam irradiance result in lower weld pool temperature for the same weld speed reducing volatile alloy constituent loss.

With the above observations, an empirically based procedure can be formulated to aid welding process development and assess the weldability of a metal given its thermophysical properties:

1. Determine the threshold irradiance for welding using the thermophysical properties, process parameters and equation (1).

2. Compare the viscosity and surface tension of the molten metal with the values for iron and aluminum. If the irradiance is high ( $\left.>1 \mathrm{MW} \mathrm{cm}^{-2}\right)$ and the viscosity and surface tension values are similar to those of aluminum, weldability problems can be expected. Otherwise, good weldpool stability and surface weld quality are expected. Metallurgical properties would have to be accounted for overall weld quality.

3. If weldability problems are indicated, examine methods for reducing threshold irradiance by increasing spot size and absorptivity by using a shorter wavelength beam (e.g., Nd:YAG instead of $\mathrm{CO}_{2}$ ). Reduce spot size if dropout becomes a problem. Improving part fitup will also ameliorate dropout problems.

\section{REFERENCES}

1. Mazumder, J. "Laser welding: state of the art review." J. Metals. (July 16-24, 1982).

2. Steen, W.M. (1991) Laser Material Processing. Springer-Verlag, London.

3. Matsunawa, A., J.-D. Kim, S. Katayama, and V.V. Semak. "Experimental and theoretical studies on keyhole dynamics in laser welding." Proceedings of Laser Materials Processing Symposium (ICALEO'96). (October 14-17, 1996).

4. Mohanty, P.S., T. Asghari, and J. Mazumder. "Experimental study on keyhole and meltpool dynamics in laser welding." Proceedings of Laser Materials Processing Symposium (ICALEO'96). (October 14-17, 1996).

5. Leong, K.H., H.K. Geyer, K.R. Sabo and P.G. Sanders. "Threshold Laser Beam Irradiances for Melting and Welding." J. Laser Applications. Vol. 9:(1997). pp. 227-231.

6. Nonhof, C. J. (1988) Material processing with Nd-lasers. Electrochemical Publications, Ayr, Scotland.

7. Grigoryants, A. G. (1994) Basics of Laser Material Processing. Mir Publishers, Moscow. 
8. Leong, K.H., K.R. Sabo, B. Altshuller, T.L. Wilkinson and C.E. Albright. "Laser beam welding of 5182 aluminum alloy sheet." Submitted to J. Laser Applications. (1998).

9. Leong, K.H., K.R. Sabo, P.G. Sanders, and W.J. Spawr. "Laser Beam Welding of Aluminum Alloys." SPIE Proceedings, Lasers as Tools for Manufacturing_II. Vol. 2993:(1997).

10. Martukanitz, R.P., D.J. Smith, F.G. Armao, A. Baldantoni, and E.R. Pickering. "Laser beam welding of aluminum alloys for automotive applications." Proceedings of the Society of Automotive Engineers International Congress and Exposition. (February 28-March 3, 1994).

11. Martukanitz, R.P., B. Altshuller, F.G. Armao, and E.R. Pickering. "Properties and characteristics of laser beam welds of automotive aluminum alloys." Proceedings of the Society of Automotive Engineers International Congress and Exposition. (1996).

12. Berkmanns, J., R. Imhoff, K. Behler and E. Beyer. "Laser welding of aluminum." Proceedings Automotive Laser Applications Workshop (ALAW'95). (March 6-7, 1995).

13. Pak, S.W., K.H. Kim, S.Y. Kwon, and W.S. Cho. "A study on the joining technology of aluminum alloy sheets for autobody application." Light Materials for Transportation Systems. N.J. Kim, ed. Center for Advanced Aerospace Materials. (1993). pp. 643-655.

14. Sanders, P.G., J.S. Keske, K.H. Leong, and G. Kornecki. "High power Nd:YAG and

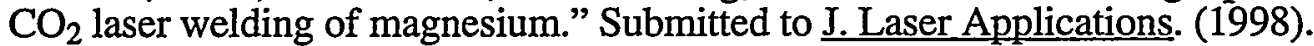

15. Iida, T. and R.I.L. Guthrie. (1993) The Physical Properties of Liquid Metals. Oxford University Press, New York.

16. Smithells, C.J., E.A. Brandes and G. Brook. (1991) Smithell's Metals Reference Book. Butterworth-Heinemann, Oxford.

17. Toulokian, Y.S., R.W. Powell, C.Y. Ho, and M.C. Nicolaou. (1970) "Thermal Conductivity Metallic Elements and Alloys." Thermophysical Properties of Matter. Vol. 1. IFI/Plenum, New York.

18. Toulokian, Y.S., R.W. Powell, C.Y. Ho, and M.C. Nicolaou. (1973) "Thermal Diffusivity." Thermophysical Properties of Matter. Vol. 10. IFI/Plenum, New York.

19. Stern, G. "Absorptivity of $\mathrm{cw} \mathrm{CO}_{2}, \mathrm{CO}$ and $\mathrm{YAG}$-laser beams by different metallic alloys." ECLAT"90 Proc. 3rd European Conf. On Laser Treatment of Materials, Erlangen, Germany, (September 17-19, 1990). pp. 25-35.

20. Prokhorov, A.M., V. Konov, I. Ursu, and I.N. Mihailescu. (1990) Laser Heating of Metals. Adam Hilger. New York.

21. Guizzetti, G. and A. Piaggi. (1991) Vanadium in Handbook of Optical Constants of Solids II. E.D. Palik, ed. Academic Press, New York.

22. Hüttner, B. "Optical Properties of Polyvalent Metals in the Solid and Liquid State: Aluminum." J. Phys. Condensed Matter. Vol. 6:(1994). pp. 2459-2474. 